\title{
BIOGENESIS OF SILVER NANOPARTICLES FROM AGRO-WASTE
}

\author{
KANCHANA $\mathrm{R}^{1,2 *}$, APURVA FERNANDES ${ }^{1}$
}

${ }^{1}$ Department of Biotechnology, Goa University, Goa, India. ${ }^{2}$ Department of Biotechnology, Parvatibai Chowgule College of Arts and Science (Autonomous), Margao, Goa, India. Email: rkr002@chowgules.ac.in

Received: 09 October 2019, Revised and Accepted: 08 November 2019

ABSTRACT

Objective: Biogenesis of multifunctional silver nanoparticles (SNPs) using agro-wastes (paddy straw [PS] and sugarcane bagasse [SB]) was reported in this study that could be deployed for biomedical and environmental applications.

Methods: The SNPs were synthesized using agro-waste extracts and the synthesized SNPs were characterized by ultraviolet (UV)-visible spectrophotometry, scanning electron microscopy, Fourier-transform infrared (FTIR) spectroscopy, and energy dispersion spectral (EDS) analysis and evaluated for their multifunctional applications.

Results: UV-visible absorption scan of SNP revealed a broad peak at $420 \mathrm{~nm}$ indicative of the surface plasmon resonance using $10 \mathrm{mM}$ silver nitrate with the reaction time of $24 \mathrm{~h}$ for PS SNP and 10 min for SB SNP. The synthesized SNPs were of size ranges from 50 to 70 nm. The SNPs were investigated to evaluate the antimicrobial activity against pathogens, efficacy in sewage water treatment and in biofilm inhibition.

Conclusion: This study has demonstrated the eco-friendly synthesis of SNPs using the agro-wastes. The synthesized NPs displayed remarkable antimicrobial activity, biofilm inhibition, and in sewage water treatment. These activities have shown that these NPs can find useful biomedical and environmental applications.

Keywords: Agro-waste, Antimicrobial, Biofilm inhibition, Biogenesis, Energy dispersion spectral, Fourier transform infrared, Paddy straw, Scanning electron microscopy, Sugarcane bagasse.

(C) 2020 The Authors. Published by Innovare Academic Sciences Pvt Ltd. This is an open access article under the CC BY license (http://creativecommons. org/licenses/by/4. 0/) DOI: http://dx.doi.org/10.22159/ajpcr.2020.v13i1.36014

\section{INTRODUCTION}

Nanotechnology is a rapid growing field in science and technology for the purpose of creating new materials at the nanoscale level. The nanoparticles (NPs) can play a vibrant role in the field of nanomedicines such as health care and medicine diagnostic and screening purposes and drug delivery systems. Metal NPs have a high specific surface area and a high fraction of surface atoms. Due to the distinct physicochemical characteristics of NPs, they are gaining the attention of scientist for their unique methods of synthesis [1]. Nanoscale particles provide a new generation of environmental remediation technologies that could provide cost-effective solutions to some of the most challenging environmental cleanup problems $[2,3]$.

Recently, biosynthetic methods employing either microorganisms or plants extract have emerged as an alternative to more complex chemical synthetic procedures to obtain nanomaterials. Although chemical method of synthesis requires a short period of time for the synthesis of large quantity of NPs, it requires capping agents for size stabilization of the NPs that are toxic and leads to non-eco-friendly by-products. The necessity for environmental non-toxic protocols for NPs synthesis leads to the developing interest in biological approaches which are free from the use of toxic chemicals. Thus, there is an increasing need for "Green Nanotechnology" [4].

The major benefit of using plant extracts for NP synthesis is that they are easily available, safe, and non-toxic in most cases, have a wide variety of metabolites that can assist in the reduction of silver ions, and are quicker than microbes in the synthesis [1]. With the vast plant diversity, much more plant species are in the way to be exploited and reported in future era toward rapid and single-step protocol with green principle. The plant phytochemicals such as terpenoids, flavonoids, and alkaloids present in the aqueous leaf extract with antioxidant property were responsible for the preparation of metal NPs [4].
However, limited literature is available on silver NPs (SNP) synthesis by agro-wastes with diverse applications. Hence, in the present investigation, we report a simple economic synthesis of SNPs by an environmental-friendly procedure involving the in situ reduction of silver by agro-wastes and evaluation of the multiapplications of the synthesized SNPs.

\section{METHODS}

\section{Synthesis of SNPs}

Approximately $5 \mathrm{~g}$ of thoroughly washed paddy straw (PS)/sugarcane bagasse (SB) was boiled in $100 \mathrm{ml}$ of distilled water for $10 \mathrm{~min}$. The suspension was cooled and filtered. SNP synthesis was carried out by mixing $90 \mathrm{ml}$ of the filtrate with $10 \mathrm{ml}$ of aqueous solution of $10 \mathrm{mM}$ silver nitrate $\left(\mathrm{AgNO}_{3}\right)$. The mixture was incubated till a color change was obtained and centrifuged at $10,000 \mathrm{rpm}$ for $20 \mathrm{~min}$. The pellet obtained was washed repeatedly with sterile distilled water, dried, and finely powdered for characterization $[4,5]$. The possibility of controlling the reaction rate was further investigated using various concentrations of substrate $\mathrm{AgNO}_{3}(0.5-25 \mathrm{mM})$ and $\mathrm{pH}$ of the extract (7.0-9.0).

\section{Characterization of SNP}

The synthesized SNPs were characterized by ultraviolet (UV)-visible spectrophotometry, scanning electron microscopy (SEM), Fouriertransform infrared (FTIR) spectroscopy, and energy dispersion spectral (EDS) analysis. UV-visible spectral analysis was done using spectrophotometer (Chemito UV 2300) by measuring the absorbance from $300 \mathrm{~nm}$ to $600 \mathrm{~nm}$. SEM analysis was carried out to characterize particle shape, distribution, and approximate size. Dry powdered sample was coated with $80 \%$ gold and $20 \%$ palladium with quorum SC7620 sputter coater to make them conductive and analyzed with Zeiss Evo 18, SEM. FTIR spectroscopy analysis of the dried SNP was done using Shimadzu FTIR spectrometer and spectrum was recorded in the range of $500-4000 \mathrm{~cm}^{-1}$ at a resolution of $4 \mathrm{~cm}^{-1}$. For EDS analysis, 
the dried, powdered SNPs were coated with gold and analyzed using Jeol instrument JSM-5800LV (Japanese Electro-Optics Ltd.)

\section{Applications of SNP}

Evaluation of antimicrobial activity

The antibacterial activity of SNPs was carried out using the well diffusion assay against test pathogens [6]. The antifungal activity of SNPs was carried out using Penicillium sp., Rhizopus sp., Fusarium sp., and Aspergillus niger as test cultures. Wells were punched into the PDA plates inoculated with the respective fungal cultures and SNP solutions $(10 \mu \mathrm{g} / \mathrm{ml})$ were added in the respective wells. The plates were incubated and inhibition diameters were measured. Well without SNP solutions served as control [7].

Determination of minimum inhibitory concentration (MIC) of test pathogens

The MIC of SNP against the test pathogens Bacillus subtilis, Staphylococcus aureus, Escherichia coli, and Proteus vulgaris was calculated by microbroth dilution method in 96-well microtiter plates using resazurin indicator solution [8]. The lowest concentration at which no color change occurred was recorded as the MIC against the respective clinical pathogens.

\section{Biofilm inhibition}

Biofilm inhibition assay was carried out using B. subtilis [9]. The percentage inhibition of biofilm activity was calculated using the following equation.

$$
\text { Percentage inhibition }=\frac{(\text { OD of sample }- \text { OD of control })}{\text { OD of control }} \times 100
$$

\section{Wastewater treatment using SNP-coated stones}

The colloidal solutions of SNP were coated onto stones to check their efficacy in water treatment. Sterile stones coated with SNP were dipped in $100 \mathrm{ml}$ domestic sewage water sample with CFU more than $10^{12}$, incubated overnight, spread plated on nutrient agar plates, and observed for the reduction in bacterial growth [10].

\section{RESULTS AND DISCUSSION}

\section{Synthesis of SNPs}

Reduction of silver ions to SNP was visualized by color change from orange to brownish-black, within 24 h for PS SNP (Fig. 1a) and yellow to dark brown in $10 \mathrm{~min}$ for SB SNP (Fig. 1b). At present, the mechanism of biological NP synthesis is not fully understood. Recent results with Capsicum annuum L. extract indicate that the proteins which have amine groups play a reducing and controlling role in the formation of SNPs in the solution. Therefore, more elaborate studies are required to elucidate the mechanism of biological NP synthesis [11]. The formation and stability of the reduced SNPs in the colloidal solution were monitored by UV-visible spectrophotometer analysis. The UV-visible spectra showed maximum absorbance at $420 \mathrm{~nm}$ (Fig. 2). The optimum concentration for the synthesis was found to be $10 \mathrm{mM}$ for PS SNP and $20 \mathrm{mM}$ for SB SNP (Fig. 3a and b) and the optimum pH for the synthesis was found to be 7.0 (Fig. $4 \mathrm{a}$ and b). Although further increase in the concentration of $\mathrm{AgNO}_{3}$ reduced the time required for NP production by the extract, higher concentration and higher $\mathrm{pH}$ lead to aggregation of NPs which cause them to precipitate out of the solution.

The UV-visible spectra showed that maximum absorbance at $420 \mathrm{~nm}$ is a characteristic of this noble metal particle which is due to the surface plasmon resonance of SNPs (Fig. 2) [12]. SEM analysis provided further insight into the morphology and size details of the SNPs. The analyzed samples showed particles with spherical morphology and the approximate particle size for PS SNP was $62 \mathrm{~nm}$ and for SB SNP $48 \mathrm{~nm}$ (Fig. 5a and b). High density of SNP was seen in the SEM image. FTIR measurements were carried out to identify the biomolecules responsible for capping and efficient stabilization of the synthesized NPs. The FTIR spectra of PS SNP (Fig. 6a) showed bands between 3400 and $3250 \mathrm{~cm}^{-1}$ which correspond to $\mathrm{N}-\mathrm{H}$ stretch $1^{\circ}, 2^{\circ}$ amines and amides. Band at $1650 \mathrm{~cm}^{-1}$ corresponds to $\mathrm{N}-\mathrm{H}$ bend, $1^{\circ}$ amines. Band between 1335 and $1000 \mathrm{~cm}^{-1}$ corresponds to $\mathrm{C}-\mathrm{N}$ stretch aromatic amines, $\mathrm{C}-\mathrm{O}$ stretch alcohols, carboxylic acids, esters, and ethers. For SB SNP (Fig. 6b), bands between 1250 and $1020 \mathrm{~cm}^{-1}$ correspond to $\mathrm{C}-\mathrm{N}$ stretch aliphatic amines. Bands between 1600 and 1585 correspond to $\mathrm{C}-\mathrm{C}$ stretch (in-ring) aromatics. Band between 1680 and $1640 \mathrm{~cm}^{-1}$ corresponds to $-\mathrm{C}=\mathrm{C}$ - stretch alkenes. Band between 3640 and $3250 \mathrm{~cm}^{-1}$ corresponds to free hydroxyl alcohols, phenols, $\mathrm{H}$-bonded alcohols, phenols, and $1^{\circ}, 2^{\circ}$ amines and amides. Therefore, the FTIR analysis confirmed that the synthesized NPs were surrounded by proteins and metabolites such as terpenoids which result in capping of SNP to prevent agglomeration and thereby stabilize the medium. This suggests that the biological molecules could possibly perform dual functions of formation and stabilization of SNP in the aqueous medium.

Silver is revealed as the major constituent element from EDS analysis (Fig. 7a and b). The optical absorption peak is observed approximately at $3 \mathrm{keV}$, which is typical for the absorption of metallic silver nanocrystallites due to surface plasmon resonance. Percentage of silver in PS SNP and SB SNP was found to be $66.76 \%$ and $73.72 \%$ by weight, respectively. Other minor weak signals indicate the presence of capping material which is another advantage of NPs synthesized using biological extracts over those synthesized using chemical method [13].

\section{Applications of SNP}

Antimicrobial activity

The antimicrobial activity of SNPs synthesized by green route was investigated against various pathogenic organisms and the result is shown in Table 1. Antimicrobial activity depends on the size and shape of the SNPs. Small size NPs have large surface area ensuring the inhibition of microbial growth [11]. Due to the abundance of sulfurcontaining proteins on the bacterial cell membrane, NPs can react with sulfur-containing amino acids inside or outside the cell membrane,
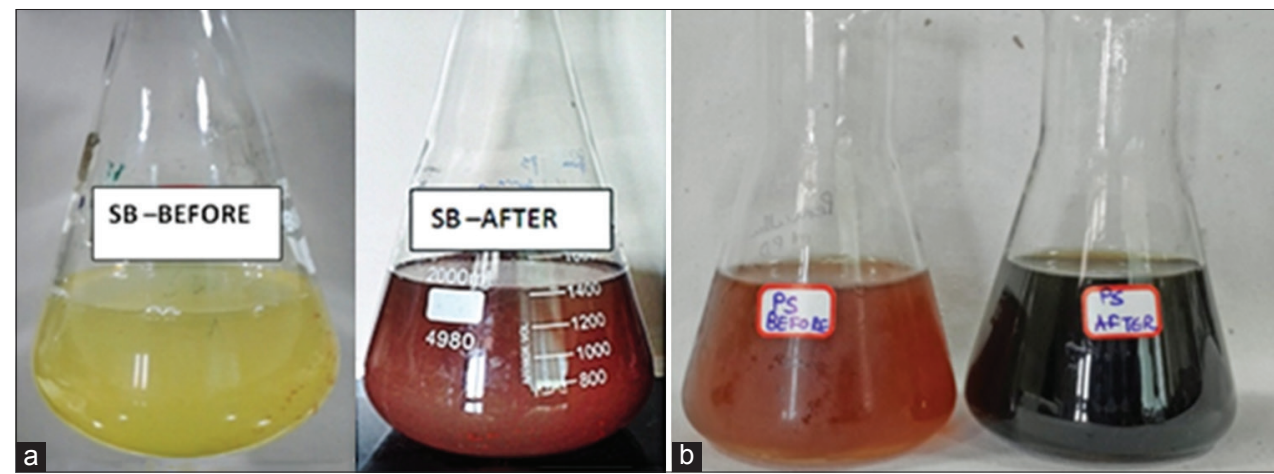

Fig. 1: (a) Biogenesis of SNP from sugarcane bagasse. (b) Biogenesis of SNP from paddy straw 


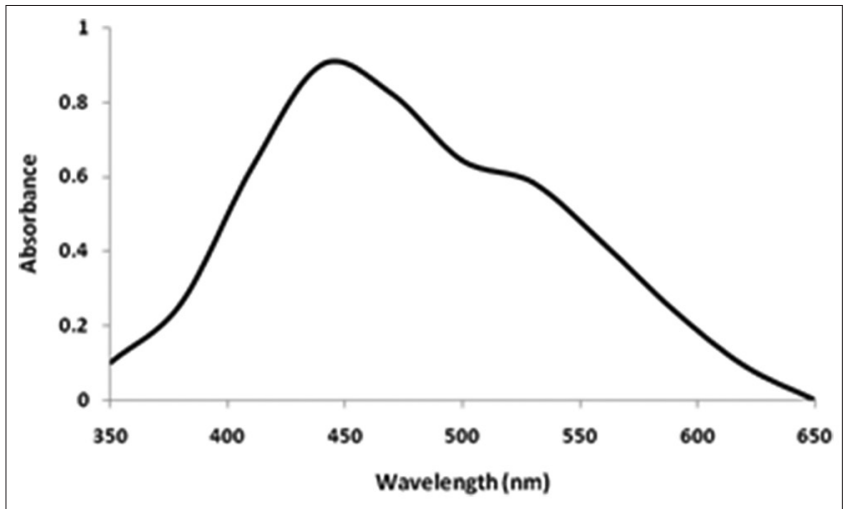

Fig. 2: Ultraviolet-visible spectrum of silver nanoparticle which, in turn, affects bacterial cell viability. It has been hypothesized that NPs primarily affect the functions of membrane-bound enzymes resulting in the loss of cellular integrity and osmotic culminating in acute toxicity to fungal cells [14]. The mechanism of antifungal activity of SNPs is not fully known. A few literature illustrated the possible mechanism of antifungal activity. Antifungal activity depends on the size and shape of the SNPs. Small size NPs have large surface area ensuring the inhibition of microbial growth. Positively charged silver ions may attach with negatively charged cell membranes of microbes by electrostatic attraction. SNPs form the pits in the cell wall and damage the cell permeability and induce the proton leakage caused by reactive oxygen species in the membrane resulting in cell death $[4,15]$.

\section{MIC of test pathogens}

The results of MIC (Table 2) suggest that SNPs exhibited excellent bactericidal effects against test cultures. Although many reports

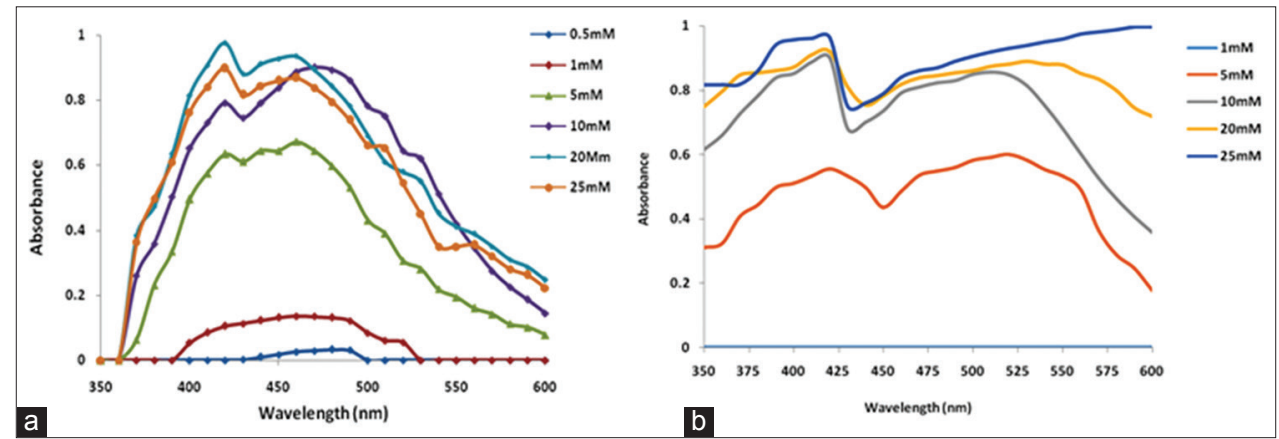

Fig. 3: (a) Effect of silver nitrate $\left(\mathrm{AgNO}_{3}\right)$ on the synthesis of SNP from sugarcane bagasse. (b) Effect of $\mathrm{AgNO}_{3}$ on the synthesis of SNP from paddy straw

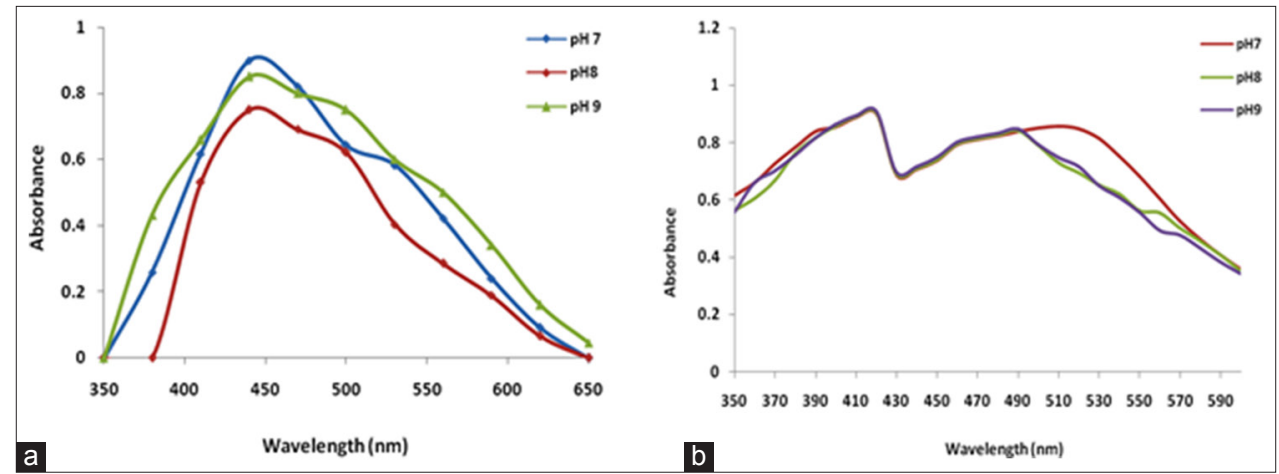

Fig. 4: (a) Effect of $\mathrm{pH}$ on the synthesis of SNP from sugarcane bagasse. (b) Effect of $\mathrm{pH}$ on the synthesis of SNP from paddy straw

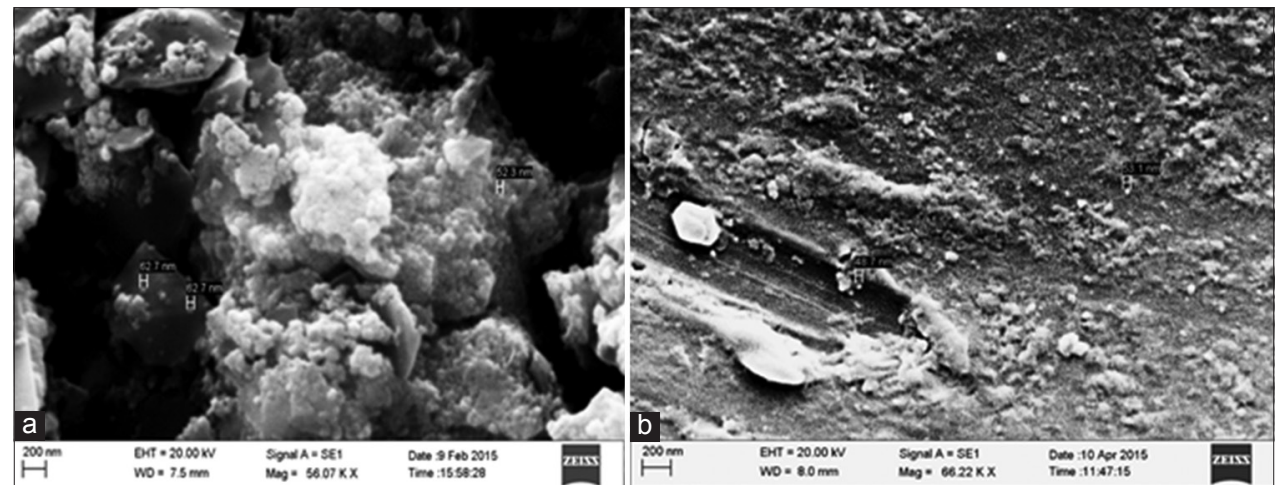

Fig. 5: (a) Scanning electron microscopy (SEM) image of SNP from paddy straw. (b) SEM image of SNP from sugarcane bagasse 


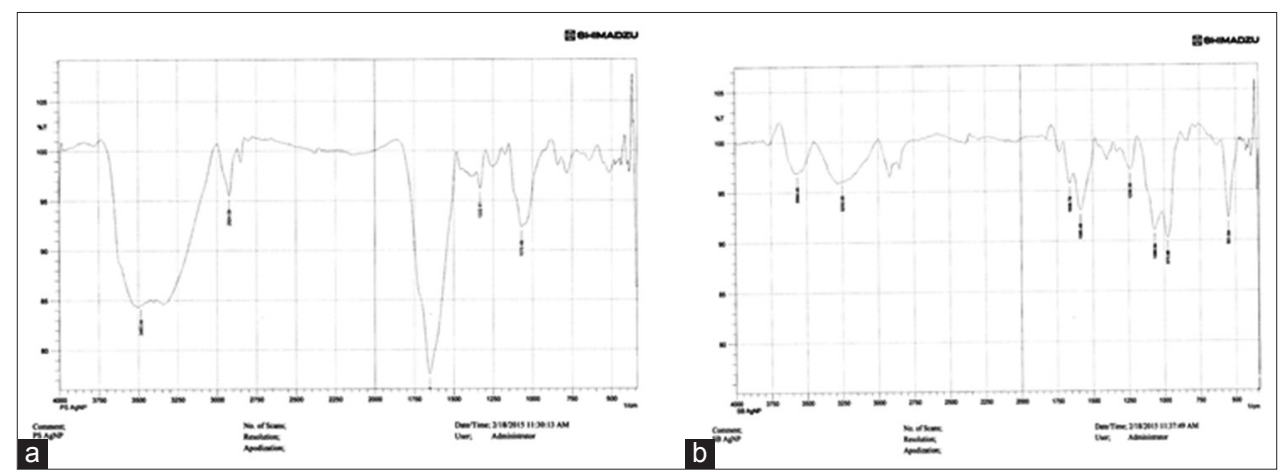

Fig. 6: (a) Fourier transform infrared (FTIR) spectrum of SNP from paddy straw. (b) FTIR spectrum of SNP from sugarcane bagasse

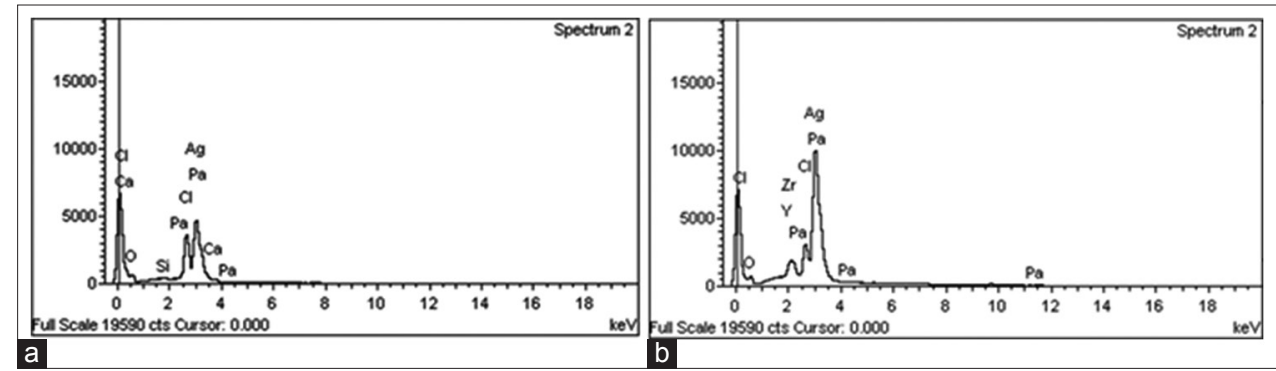

Fig. 7: (a) Energy dispersion spectral (EDS) analysis of SNP from paddy straw. (b) EDS analysis of SNP from sugarcane bagasse

Table 1: Antimicrobial activity SNP

\begin{tabular}{|c|c|c|c|c|c|}
\hline \multirow[t]{3}{*}{ Sample } & \multirow[t]{3}{*}{ Concentration $(\mathrm{mg} / \mathrm{ml})$} & \multicolumn{4}{|l|}{ Antibacterial activity } \\
\hline & & \multicolumn{4}{|c|}{ Inhibition diameter (mm) } \\
\hline & & Staphylococcus aureus & Bacillus sp. & Proteus sp. & Escherichia coli \\
\hline PS SNP & 12 & $18.33 \pm 1.52$ & $20.0 \pm 2.0$ & $18.0 \pm 0.0$ & $18.6 \pm 0.57$ \\
\hline SB SNP & 12 & $18.3 \pm 1.15$ & $18.0 \pm 1.0$ & $16.6 \pm 0.57$ & $17.6 \pm 0.57$ \\
\hline \multirow[t]{3}{*}{$\mathrm{AgNO}_{3}$} & $20 \mathrm{mM}$ & $09.6 \pm 0.57$ & $08.6 \pm 0.57$ & $07.6 \pm 0.57$ & $08.6 \pm 0.57$ \\
\hline & & \multicolumn{4}{|l|}{ Antifungal activity } \\
\hline & & Rhizopus sp. & Fusarium sp. & Aspergillus niger & Penicillium sp. \\
\hline PS SNP & 12 & $13.3 \pm 0.57$ & $14.0 \pm 1.0$ & $12.3 \pm 0.57$ & $14.3 \pm 0.57$ \\
\hline SB SNP & 12 & $11.0 \pm 0.0$ & $11.6 \pm 0.57$ & $10.6 \pm 0.57$ & $10.3 \pm 0.57$ \\
\hline $\mathrm{AgNO}_{3}$ & $20 \mathrm{mM}$ & $6.4 \pm 0.3$ & $5.4 \pm 0.3$ & $6.4 \pm 0.3$ & $7.4 \pm 0.3$ \\
\hline
\end{tabular}

*Well diffusion method on LB agar/PDA plate for antibacterial/antifungal activity, respectively, and the zone of clearance was measured after the incubation period. Values are presented as mean \pm SD of the three triplicates of the experiments. SD: Standard deviation, SNP: Silver nanoparticle, PS: Paddy straw, SB: Sugarcane bagasse, $\mathrm{AgNO}_{3}$ : Silver nitrate

Table 2: MIC of SNP against test cultures

\begin{tabular}{lllll}
\hline Sample & MIC $(\boldsymbol{\mu g} / \mathbf{m l})$ & & \\
\cline { 2 - 5 } & Escherichia coli & Staphylococcus aureus & Bacillus sp. & Proteus sp. \\
\hline PS SNP & $20 \pm 0.2$ & $20 \pm 0$ & $20 \pm 0.8$ & $40 \pm 1.6$ \\
SB SNP & $20 \pm 0.5$ & $30 \pm 1.2$ & $20 \pm 0.9$ & $50 \pm 2.5$ \\
\hline
\end{tabular}

SNP: Silver nanoparticle, PS: Paddy straw, SB: Sugarcane bagasse, MIC: Minimum inhibitory concentration

showed the antibacterial effect of SNP synthesized from microbes, the present study emphasizes the elimination of the complicated process of maintaining the microbial culture for NPs synthesis, thus reducing the cost of NP synthesis.

\section{Biofilm inhibition}

Biofilm infections are extremely challenging to treat because antimicrobials are less effective. The presence of biofilm causes numerous problems in the field of medicine as well as marine biofouling; it interferes with the clinical therapy of chronic and wound-related infections as well as persistent infections of various medical devices. Although numerous strategies have been established and are currently in use to control biofilm, the search for novel, natural, and effective antibiofilm agents still continues. In the present study, the use of NPs as alternatives to control biofilms has been explored. Compared to the control, preformed B. subtilis biofilms treated with SNP $(12 \mu \mathrm{g} / \mathrm{ml})$ for $24 \mathrm{~h}$ showed inhibition of $78.92 \%$. SNPs have been shown to modify the surface properties of bacterial cells and reduce their adhesive properties [9] 


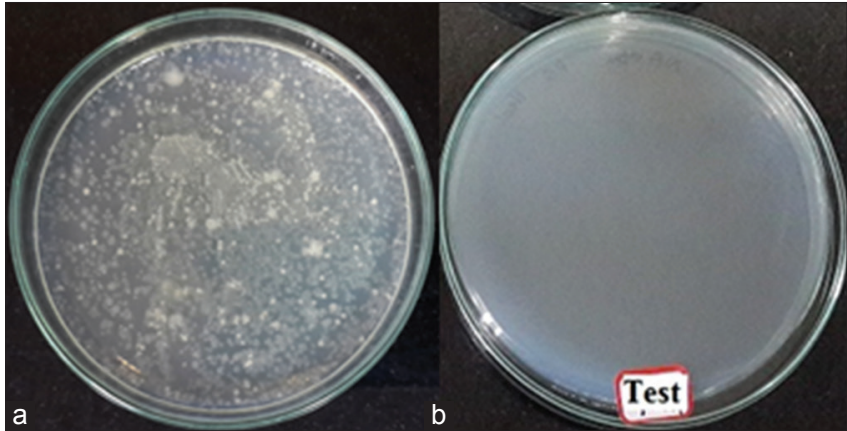

Fig. 8: ( $a$ and b) Sewage water treatment using silver nanoparticle

The result of the present study reveals that biologically synthesized SNPs not only effectively inhibited the growth of the bacteria but also wiped out the biofilm formed by it which may due to be the presence of water channels though out the biofilm. Since in all biofilms water channels (pores) are present for nutrient transportation, SNP may directly diffuse through the exopolysaccharide layer through the pores and may impart antimicrobial function. This study thus demonstrates the futuristic application of SNPs as a potential antibiofilm agent. Similar report by Kalishwaralal et al. [16] showed that SNP eliminated the biofilm formed previously besides inhibiting the formation of biofilm in existing bacteria.

\section{Wastewater treatment using SNP-coated stones}

The application of SNPs as an effective agent for sewage water treatment clearly shows no bacterial growth on the plate spread plated with water sample treated with the stones coated with SNP as compared to the control plate (Fig. 8). Thus, agro-waste generated SNPs can be effectively used in sewage water treatment, as well where stones can be used in the form of a filter, through which water when passed, can be purified. The results obtained were consistent with those obtained previously by Saklani and Jain [17].

\section{CONCLUSION}

It has been demonstrated that the agro-waste is capable of producing SNPs. The biosynthesized SNPs showed excellent antimicrobial activity, in water treatment and biofilm inhibition property. Thus, the biologically synthesized SNPs could be of immense use in medical field. Based on these findings, the current method can be suitable for the industrialscale production of SNP from a commonly burning agricultural waste.

\section{ACKNOWLEDGMENT}

The authors gratefully acknowledge Goa University, Goa, India, where the above-mentioned research study was carried out and the National Institute of Oceanography, Dona Paula, Goa, India, for providing the facilities of FTIR spectroscopy, EDS analysis, and microtiter plate reader.

\section{AUTHORS' CONTRIBUTIONS}

The corresponding author has designed the work and prepared the manuscript. The second author has carried out the experimental work.

\section{CONFLICTS OF INTEREST}

Nil.

\section{REFERENCES}

1. Logeswari P, Silambarasan S, Abraham J. Synthesis of silver nanoparticles using plants extract and analysis of their antimicrobial property. J Saudi Chem Soc 2012;19:311-17.

2. Li S, Qui L, Shen Y, Xie A, Yu X, Zhang L, et al. Green synthesis of silver nanoparticles using Capsicum annum L. Extract. Green Chem 2007;9:852-58.

3. Kalifawi EJ. Green synthesis of magnetite iron oxide nanoparticles by using Al-abbas's (A.S) hund fruit (Citrus medica) var. sarcodactylis Swingle extract and used in Al-Alqami river water treatment. J Nat Sci Res 2015;5:125-35.

4. Rajeshkumar S, Malarkodi C, Paulkumar K, Vanaja M, Gnanajobitha G, Annadurai G. Algae mediated green fabrication of silver nanoparticles and examination of its antifungal activity against clinical pathogens. Int J Metals 2014;1:1-8.

5. Dhanasekaran S, Karunakaran S, Amutha R, Priyadharshini SS, Jayalakshmi K. Biosynthesis of silver nanoparticles using Acorus calamus and its antibacteral activity. Int $\mathrm{J}$ Nanomater Biostruct 2014;4:16-20

6. Singh K, Panghal M, Kadyan S, Chaudary U, Yadav PJ. Antibacterial activity of synthesized silver nanoparticles from Tinospora cordifolia against multi drug resistant strains of Pseudomonas aeruginosa isolated from burn patients. J Nanomedecine Nanotechnol 2014;5:1-6.

7. Nadia KG, Howida KT, Mansoura ZI, Hemat MM. Silver nanoparticles: Effect on antimicrobial and antifungal activity of new heterocycles. Bull Korean Chem Soc 2010;31:3530-38.

8. Sarker SD, Nahar L, Kumarasamy Y. Microtitre plate-based antibacterial assay incorporating resazurin as an indicator of cell growth, and its application in the in vitro antibacterial screening of phytochemicals. Methods 2007;42:321-24.

9. Sambanthamoorthy K, Feng X, Patel R, Patel S, Paranavitana C. Antimicrobial and antibiofilm potential of biosurfactants isolated from lactobacilli against multi-drug-resistant pathogens. BMC Microbiol 2014;14:1-9

10. Nanda A, Saravanan M. Biosynthesis of silver nanoparticles from Staphylococcus aureus and its antimicrobial activity against MRSA and MRSE. Nanomedicine 2009;5:452-56.

11. Gurunathan S, Kalishwaralal K, Vaidyanathan R, Venkataraman D, Pandian SR, Muniyandi J, et al. Biosynthesis, purification and characterization of silver nanoparticles using Escherichia coli. Colloids Surf B Biointerfaces 2009;74:328-35.

12. Seshadri S, Prakash A, Kowshik M. Biosynthesis of silver nanoparticles by marine bacterium Idiomarina sp. PR58-8. Bull Mater Sci 2012;35:1201-05.

13. Shankar SS, Rai A, Ahmad A, Sastry M. Rapid synthesis of Au, Ag, and bimetallic au core $\mathrm{Ag}$ shell nanoparticles using neem (Azadirachta indica) leaf broth. J Colloid Interface Sci 2004;275:496-02

14. Kanchana R, Zantye P. Plant-mediated synthesis of silver nanoparticles with diverse applications. Asian J Pharm Clin Res 2016;9:159-63.

15. Sulaiman GM, Mohammed WH, Marzoog TR, Al-Amiery AA, Kadhum AA, Mohamad AB. Green synthesis, antimicrobial and cytotoxic effects of silver nanoparticles using Eucalyptus chapmaniana leaves extract. Asian Pac J Trop Biomed 2013;3:58-63.

16. Kalishwaralal K, Kanth SB, Pandian SR, Deepak V, Gurunathan S. Silver nanoparticles impede the biofilm formation by Pseudomonas aeruginosa and Staphylococcus epidermidis. Colloids Surf B Biointerfaces 2010;79:340-44.

17. Saklani V, Jain SV. Microbial synthesis of silver nanoparticles: A review. J Biotechnol Biomat 2012;13:1-3. 